\title{
AS PRODUÇÕES ESCRITAS DE SUJEITOS SURDOS
}

\author{
Writing by deaf subjects
}

Ana Cristina Guarinello*e Reny Maria Gregolin **

$\mathrm{A}$ elaboração deste trabalho originou-se da minha inquietação com relação à aquisição da língua portuguesa em sua modalidade escrita por sujeitos surdos. Parecia que o fato dos sujeitos surdos apresentarem dificuldades ao adquirir a linguagem escrita se relacionava com as metodologias educacionais empregadas com esses sujeitos, que se baseavam, muitas vezes, em estratégias descontextualizadas e repetitivas. Além disso, foi possível observar que muitos estudos realizados por educadores, psicólogos, fonoaudiólogos e lingüistas, destacavam as dificuldades e as diferentes construções escritas dos surdos; alguns se detinham na sua escrita considerada "atípica"; outros na interferência da língua de sinais nas construções escritas; outros na condição da surdez, e havia, ainda, os que relacionavam a escrita a técnicas pedagógicas inadequadas. Porém, poucas eram as propostas para o desenvolvimento da escrita. Deste modo, muitos surdos continuam com dificuldades para aprender a ler e a escrever, e um grande número deles não tem acesso a práticas discursivas significativas que propiciem o domínio da linguagem escrita.

* Autora da Tese de Doutorado "O papel do outro no processo de construção de produções escritas por sujeitos surdos” (Universidade Tuiuti do Paraná)

** Orientadora (Universidade Federal do Paraná) 
Como conseqüência dessa inquietação, o objetivo deste trabalho ${ }^{1}$ foi analisar produções escritas de um sujeito surdo com base na lingüística textual, principalmente à luz do conceito de referenciação, como proposto por Koch e Marcuschi (2002) e o de retextualização, como apresentado por Marcuschi (2001). Esse ramo da lingüística foi escolhido para a análise dos dados, pois permitiu que se fizesse um diagnóstico a respeito da estruturação dos textos desse sujeito, abordando principalmente a coesão e a coerência. Após esse diagnóstico que demonstrou quais as estratégias de progressão referencial, progressão tópica e coerência que o sujeito surdo utilizou, apresento o processo de retextualização, que, algumas vezes, se fez necessária para construir o sentido dos textos e aproximar do português padrão o texto original escrito pelo surdo.

$\mathrm{O}$ córpus deste estudo longitudinal é composto por produções escritas de um sujeito surdo, com 15 anos de idade. As produções foram coletadas em terapias fonoaudiológicas individuais, nas quais atuei como co-autora.

A metodologia utilizada para desenvolver a investigação e a apresentação dos dados ancorou-se em uma concepção discursiva de linguagem que privilegia diferentes trocas sociais e jogos interativos, dessa forma, parti do pressuposto de que as relações entre sujeito e linguagem são singulares. Nessa perspectiva, o desenvolvimento da escrita das crianças não segue um caminho único e igual, ao contrário, passa por um processo de imprevisibilidades e diferenças. Nessa concepção o sujeito surdo é percebido como ativo e singular, e o outro, terapeuta/ investigador, tem o papel de intérprete e de parceiro na constituição do português escrito, ou seja, atribui forma e sentido às produções da criança, intervindo, quando necessário, para transformar a escrita de forma a aproximar o seu texto do português. qual:

A base teórica está coerente com a posição assumida por Franchi, na

a linguagem é um trabalho que dá forma ao conteúdo variável de nossas experiências, trabalho de construção, de retificação do "vivido", que, ao mesmo tempo, constitui o sistema simbólico mediante o qual se opera sobre a realidade e constitui a realidade como um sistema de referências em que aquele se torna significativo. Um trabalho coletivo em que cada um se identifica com os outros

1 Cabe ressaltar que esta pesquisa faz parte da tese defendida na UFPR em março de 24, na qual foram analisados dados de escrita de quatro sujeitos surdos ao longo de dois anos de acompanhamento fonoaudiológico, porém, neste trabalho, faremos a análise de apenas três produções textuais de um dos sujeitos. 
GUARINELLO, A. C.; GREGOLIN, R. M. As produções escritas de sujeitos surdos.

e a eles se contrapõe, seja assumindo a história e a presença, seja exercendo suas opções solitárias. ${ }^{2}$

A posição adotada nesta pesquisa também está de acordo com Marcuschi, que assume uma concepção discursiva, para a qual os fatores sociais são relevantes. Para esse autor:

a língua não é um simples sistema de regras, mas uma atividade sociointerativa que exorbita o próprio código como tal. Em conseqüência, o seu uso assume um lugar central e deve ser o principal objetivo de nossa observação porque só assim se elimina o risco de transformá-la em mero instrumento de transmissão de informações. A língua é fundamentalmente um fenômeno sociocultural que se determina na relação interativa e contribui de maneira decisiva para a criação de novos mundos e para nos tornar definitivamente humanos. ${ }^{3}$

A linguagem é, então, um trabalho coletivo em que cada pessoa se identifica com outras e a elas se contrapõe. Na concepção interacionista, Coudry (1988, p.57) destaca que a língua é resultado desse trabalho coletivo, histórico e cultural; suas regras sociais derivam do jogo da linguagem por meio de sua prática. A língua então dispõe de diversos recursos expressivos que "associados a fatores como o contexto, a situação, a relação entre os interlocutores, as leis conversacionais, etc. fornecerão condições de determinação de um dado enunciado". Foi partindo dessa posição teórica, por meio do jogo dialógico da construção conjunta da significação, que esse sujeito surdo pode desenvolver e aprimorar a linguagem escrita.

Para priorizar a natureza interativa da linguagem, foram utilizados diferentes tipos de textos escritos em jornais, gibis, livros, revistas, apresentando aos sujeitos poesias, contos, fábulas, receitas, experiências, entrevista, etc. Em todas as sessões procurou-se enfatizar a escrita em contextos significativos, nos quais o sujeito fosse capaz de interiorizar a língua portuguesa e perceber sua funcionalidade.

2 FRANCHI, Carlos. Criatividade e gramática. In: Cadernos de estudos lingüisticos. Campinas: Unicamp, 1992. p. 31.

3 MARCUSCHI, Luiz Antônio. Da fala para a escrita: atividades de retextualização. São Paulo: Cortez, 2001. p. 125. 
O material coletado é composto por três produções escritas desse sujeito, produzidas ao longo de dois anos de trabalho. Cada sessão terapêutica foi acompanhada de um diário escrito por mim, para registrar os passos que o sujeito percorria no processo de escrita, como, por exemplo, se utilizava a língua de sinais, o alfabeto digital, se fazia perguntas, se recorria a mim.

$\mathrm{Na}$ análise, primeiramente apresenta-se a reprodução do texto escrito pelo sujeito e, em seguida, a análise do texto do sujeito com o viés da lingüística textual, baseados principalmente no conceito de progressão referencial de Koch e Marcuschi (2002), de progressão tópica de Koch (2003) e de coerência como fator da textualidade. A retextualização como proposto por Marcuschi (2001) é mostrada em um último momento, enfatizando quais operações foram necessárias para que o texto se aproximasse do português padrão. Esse trabalho demonstra que a investigadora teve parcelas de responsabilidade na escrita do sujeito, atuando como agente participante de atividades e nos processos de apropriação da língua portuguesa e das práticas sociais.

A seguir mostrarei a análise de três textos desse sujeito apenas a título de demonstração.

Nesse primeiro texto, $\mathrm{Uriel}^{4}$ escreveu uma notícia sobre o roubo do apartamento de sua irmã.

\section{Texto 1}

1 - Um Acontecer, ${ }^{5}$ minha irmã [1] apartamento [2], o ladrão [3] pega um ferro forçar, a porta [4] quebrou [5] abril,

2 - ele [6] pulo na dentro casa [7] andou viu todos cosia,

3 - ele [8] robrou TV. Radio, cd 70.

4 - Karina e Terezinha [9] chegou para apartamento [10],

5 - elas [11] viu subiu Tv, rádio, cd 70,

6 - ela [12] ficou chora, chora, a Terezinha ficou nervosa.

7 - Ela [13] falou para namorada também eu.

Quanto à progressão referencial nesse texto, foram selecionados quatro referentes "minha irmã", "apartamento", "ladrão" e "Karina e Terezinha".

4 Nome fictício.

5 As palavras em negrito foram aquelas que o sujeito solicitou minha ajuda, isto é, fez o sinal e eu as traduzi para lingua portuguesa. 
Para o referente "minha irmã" houve predileção pela retomada, por meio da estratégia (2), de anáfora pronominal, em [12] e [13].

\begin{tabular}{|l|l|}
\hline Minha irmã [1] & Introdução ao referente \\
Ela [12] & Anáfora pronominal (2) \\
Ela [13] & Anáfora pronominal (2) \\
\hline
\end{tabular}

Para o referente "apartamento", houve retomada por meio da estratégia (4), de anáfora nominal por sinonímia, em [7], e pela estratégia (1), de anáfora nominal por repetição lexical, em [10].

\begin{tabular}{|c|c|}
\hline Apartamento [2] & Introdução ao referente \\
\hline Casa [7] & Anáfora nominal (4) \\
\hline Apartamento [10] & Anáfora nominal (1) \\
\hline
\end{tabular}

Para o referente "ladrão", houve retomada por meio da estratégia (2), em [4], [5], [6] e [8]. Cabe ressaltar que em [4] e [5] a retomada ocorreu pela elipse.

\begin{tabular}{|c|l|}
\hline Ladrão [3] & Introdução ao referente \\
$\varnothing[4],[5]$ & Anáfora pronominal (2) \\
ele [6], [8] & Anáfora pronominal (2) \\
\hline
\end{tabular}

Para o referente "ladrão", houve retomada por meio da estratégia (2), em [4], [5], [6] e [8]. Cabe ressaltar que em [4] e [5] a retomada ocorreu pela elipse.

\begin{tabular}{|l|l|}
\hline $\begin{array}{l}\text { Karina e Terezinha [9] } \\
\text { Elas [11] }\end{array}$ & $\begin{array}{l}\text { Introdução ao referente } \\
\text { Anáfora pronominal (2) }\end{array}$ \\
\hline
\end{tabular}

Para o referente "Karina e Terezinha" houve retomada também por meio da estratégia (2) de anáfora pronominal, em [11].

Nesse texto só houve a referenciação por meio da correferenciação e da não recategorização. Cabe esclarecer que houve também uma referência ambígua 
que só pôde ser esclarecida porque eu estava junto no momento da produção. $\mathrm{Na}$ linha 6, Uriel refere que /Terezinha ficou nervosa/, e logo abaixo, na linha 7, escreve /ela falou para namorada/. A impressão que se tem quando se lê é que a Terezinha falou para o namorado, mas, na realidade, foi a irmã dele que contou para o namorado.

Quanto à coesão seqüencial, houve recorrência de tempo e aspecto verbal, já que seu texto indica uma seqüência de eventos. Os verbos são colocados sempre no presente e no passado. Não se observa a terminação verbal para o verbo na primeira pessoa do plural, nas linhas 4 /Karina e Terezinha chegou/ e 5 /elas viu/. Não há registros também de articuladores de conteúdo proposicional com marcadores de relações espaço-temporais.

Observa-se que Uriel utilizou a pontuação em todo o seu texto, e este fato fez com que seu texto ficasse bem articulado. Apesar de não ter utilizado os indicadores de relações lógico-semânticas e nem os articuladores enunciativos e meta-enunciativos.

A progressão tópica também foi notada por meio de estruturas com tema constante, isto é, a cada enunciado acrescentaram-se novas informações remáticas a um mesmo tema. Outro fator interessante notado é a recorrência de termos na linha 6, quando escreveu /ela ficou chora, chora/.

No texto 1 não houve muitas dificuldades com relação à coerência, visto que se considera que esta se constitui na interação dialógica e pressupõe uma disponibilidade dos falantes em encontrar um ponto comum de entendimento. Dessa forma, por meio da interação e da troca de informações, consegui compreender e analisar o texto, atribuindo-lhe sentido. A única questão que poderia causar certo estranhamento com relação à coerência do texto de Uriel diz respeito à referência ambígua, já comentada anteriormente.

No segundo texto, Uriel escreveu sobre o filme que havíamos assistido no cinema: Dr. Do Little II. 


\section{Texto 2}

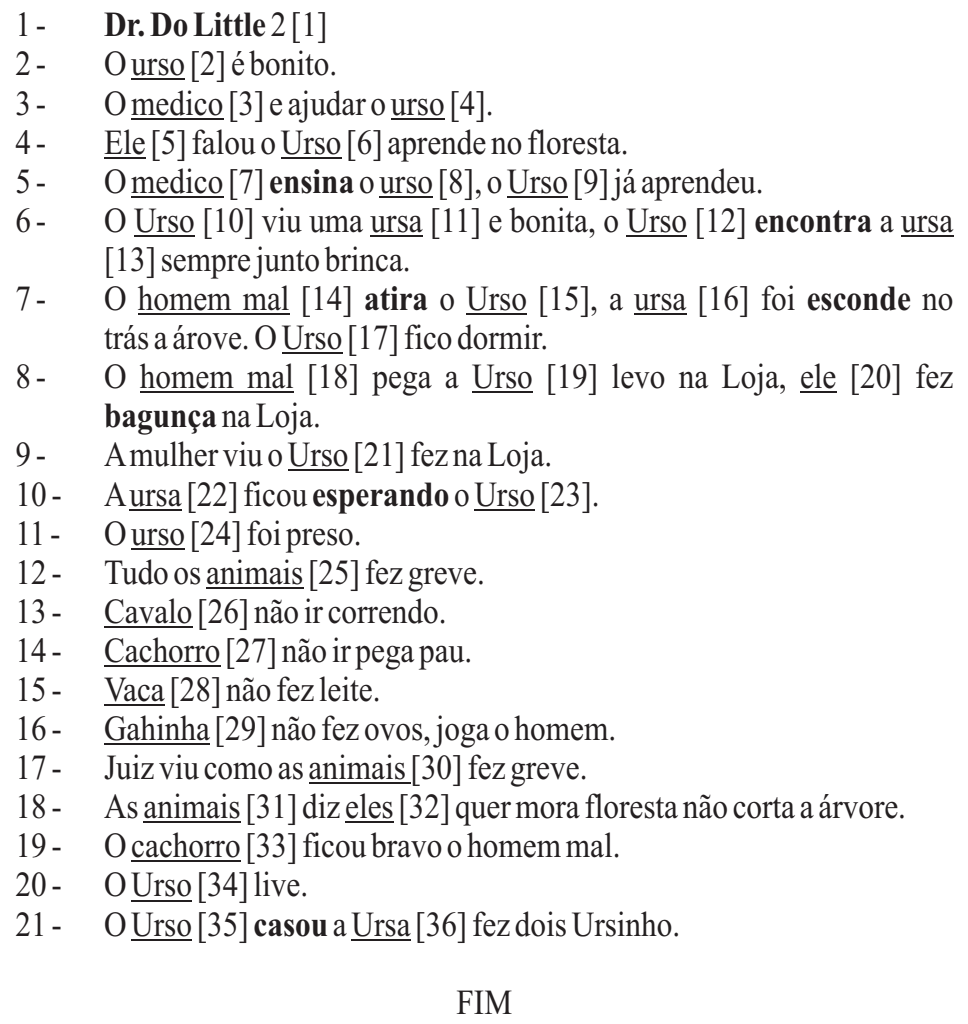

Foram selecionadas cinco cadeias anafóricas: uma para o referente "Dr. Do Little", outra para "urso", outra para "ursa", outra para "homem mal" e, por fim, uma para "animais".

Para o referente "Dr. Do Little", houve predileção pela estratégia (6), de descrição definida, em [3] e [7], e pela estratégia (2), de anáfora pronominal, em [5].

\begin{tabular}{|l|l|}
\hline $\begin{array}{l}\text { Dr, Do Little [1] } \\
\text { Médico [3], [7] }\end{array}$ & Introdução ao referente \\
Ele [5] & Ancrição definida (6) \\
\hline
\end{tabular}


Para o referente "urso", houve predileção pela estratégia (1), de anáfora nominal por repetição lexical, em [4], [6], [8], [9], [10], [12], [15], [17], [19], [21], [23], [24], [34] e [35]. Também houve retomada por meio da estratégia (2), de anáfora pronominal, em [20].

\begin{tabular}{|l|l|}
\hline Urso [2] & Introdução ao referente \\
Urso [4], [6], [8], [9], [10], [12], [15], & Anáfora nominal (1) \\
$\begin{array}{l}\text { [17], [19], [21], [23], [24], [34], [35] } \\
\text { Ele [20] }\end{array}$ & Anáfora pronominal (2) \\
\hline
\end{tabular}

Para o referente "ursa", houve predileção apenas pela estratégia (1), de anáfora nominal, em [13], [16], [22] e [36].

\begin{tabular}{|l|l|}
\hline Ursa [11] & Introdução ao referente \\
Ursa [13], [16], [22], [36] & Anáfora nominal (1) \\
\hline
\end{tabular}

Para o referente "homem mal", houve retomada apenas uma vez, em [18], também por meio da estratégia (1), de anáfora nominal.

\begin{tabular}{|l|l|}
\hline Homem mal [14] & $\begin{array}{l}\text { Introdução ao referente } \\
\text { Homem mal [18] }\end{array}$ \\
& Anáfora nominal (1) \\
\hline
\end{tabular}

E, finalmente, para o referente "animais", Uriel fez remissões, recategorizando a palavra, usando a estratégia (6), de descrição definida, em [26], [27], [28], [29] e [33]. Também utilizou a estratégia (1), de anáfora nominal, em [30] e [31] e a estratégia (2), de anáfora pronominal, em [32].

\begin{tabular}{|l|l|}
\hline Animais [25] & Introdução ao referente \\
Cavalo [26] & Descrição definida (6) \\
Cachorro [27], [33] & Descrição definida (6) \\
Vaca [28] & Descrição definida (6) \\
Gahinha [29] & Descrição definida (6) \\
Animais [30], [31] & Anáfora nominal (1) \\
Eles [32] & Anáfora pronominal (2) \\
\hline
\end{tabular}


Percebe-se que as cadeias anafóricas usadas nesse texto foram bem mais elaboradas que as do texto 1 , principalmente pelo uso da estratégia (6), de descrição definida, já que essa estratégia apresenta outras características, como a recategorização, a não correferencialidade, a não co-significação, a implicitação, a avaliação e a refocalização. Isso demonstra que Uriel está refletindo sobre o uso do português escrito, já que a referência é um problema que envolve as operações efetuadas pelos sujeitos à medida que o discurso se desenvolve; o discurso constrói aquilo a que faz remissão, ao mesmo tempo em que é tributário dessa construção.

Quanto à coesão seqüencial, nota-se em todo o texto a recorrência de tempo e aspecto verbal, e a utilização melhor dos verbos e de seus tempos, como na linha 5 /o médico ensina o urso/, na linha 6 /o urso viu uma ursa/, na linha 8 /ele fez bagunça na loja/, na linha 10 /a ursa ficou esperando o urso/, na linha 11 /o urso foi preso/, na linha 19 /o cachorro ficou bravo o homem/ e na linha 21 /o urso casou ursa/. Nesses mesmos exemplos, pode-se perceber que, ora Uriel utiliza as preposições corretamente, como na linha 8 / fez bagunça na loja/, ora não utiliza preposições, como nas linhas 19 /o cachorro ficou bravo o homem mal/ e 21 /o urso casou a ursa/.

Quanto à progressão tópica, percebe-se o uso de um tema constante, como, por exemplo, nas dez primeiras linhas, uma vez que são acrescentadas novas informações sobre um mesmo tema. Também ocorreram saltos temáticos entre um fato e outro. Um exemplo acontece entre as linhas 11 e 12, nas quais Uriel estava falando que o urso foi preso e passou a falar sobre a greve dos animais.

\section{0 urso foi preso.}

12.Tudo os animais fez greve.

Quanto ao encadeamento por justaposição, nota-se um uso maior de partículas marcadas pelos sinais de pontuação. Nesse texto não se percebe a articulação do texto por meio de indicadores de relações lógico-semânticas, e nem de articuladores discursivo-argumentativos.

Quanto à coerência textual, esta é resultado da habilidade do leitor em inferir as relações no nível da sentença que mantém o texto unido. Dessa forma, foi a partir do conhecimento partilhado que se constituiu a coerência.

Precisei apenas intervir nas linhas 11 e 12, já que não estava implícito no texto que os animais fizeram greve exatamente porque o urso foi preso.

\section{O urso foi preso.}

12.Tudo os animais fez greve.

Precisei também intervir entre as linhas 18 e 19, já que Uriel estava explicando o que os animais pediram ao juiz /as animais diz eles quer mora floresta não corta a árvore/ e, na outra linha, escreveu /o cachorro ficou bravo o homem mal/, ficando difícil para o leitor entender a relação entre uma frase e outra. A seguir apresento a retextualização desse texto. 
GUARINELLO, A. C.; GREGOLIN, R. M. As produções escritas de sujeitos surdos.

\begin{tabular}{|c|c|c|c|c|c|}
\hline TEXTO ORIGINAL & RETEXTUALIZAÇÃO & $\begin{array}{c}\text { TIPO DE } \\
\text { OPERAÇÃO }\end{array}$ & ELIMINAÇÕES & SUBSTITUIÇÕES & $\begin{array}{l}\text { ACRÉSCIMOS/ } \\
\text { ALTERAÇÕES }\end{array}$ \\
\hline $\begin{array}{l}1 \text { - Dr. Do Little } 2 \\
2 \text { - O urso é bonito. } \\
3 \text { - O medico e ajudar } \\
\text { o urso. } \\
4 \text { - Ele falou o Urso } \\
\text { aprende no floresta. } \\
\text { O medico ensina o } \\
\text { urso, o Urso já } \\
\text { aprendeu. } \\
5 \text { - O Urso viu uma } \\
\text { ursa e bonita, o Urso } \\
\text { encontra a ursa } \\
\text { sempre junto brinca. } \\
6 \text { - O homem mal } \\
\text { atira o Urso, a ursa } \\
\text { foi esconde no trás a } \\
\text { árove. O Urso fico } \\
\text { dormir. } \\
7 \text { - O homem mal } \\
\text { pega a Urso levo na } \\
\text { Loja, ele fez bagunça } \\
\text { na Loja.A mulher viu } \\
\text { o Urso fez na Loja. } \\
8 \text { - A ursa ficou } \\
\text { esperando o Urso. O } \\
\text { urso foi preso. } \\
9 \text { - Tudo os animais } \\
\text { fez greve. } \\
10 \text { - Cavalo não ir } \\
\text { correndo. Cachorro } \\
\text { não ir pega pau. Vaca } \\
\text { não fez leite. Gahinha } \\
\text { não fez ovos, joga o } \\
\text { homem. } \\
11 \text { - Juiz viu como as } \\
\text { animais fez greve. As } \\
\text { animais diz eles quer } \\
\text { mora floresta não } \\
\text { corta a árvore. } \\
12 \text { - O cachorro ficou } \\
\text { bravo o homem mal. } \\
\text { O Urso live. } \\
13 \text { - O Urso casou a } \\
\text { Ursa fez dois } \\
\text { Ursinho. }\end{array}$ & $\begin{array}{l}1 \text { - Dr. Do Little } 2 . \\
2 \text { - O filme começa } \\
\text { com um urso bonito. } \\
3 \text { - E o médico Dr Do } \\
\text { Little ajudou o urso. } \\
4 \text { - Ele falou para o } \\
\text { urso aprender na } \\
\text { floresta, e ensinou o } \\
\text { urso e este aprendeu. } \\
5 \text { - Um dia, o urso viu } \\
\text { uma ursa bonita e } \\
\text { começou a encontrá- } \\
\text { la para brincarem } \\
\text { juntos sempre. } \\
6 \text { - Mas, um homem } \\
\text { mau atirou no urso e } \\
\text { a ursa se escondeu } \\
\text { atrás de uma árvore. } \\
\text { Com o tiro, o urso } \\
\text { dormiu. } \\
7 \text { - Então o homem } \\
\text { mau pegou o urso e o } \\
\text { levou para uma loja. } \\
\text { O urso fez bagunça } \\
\text { na loja. A dona da } \\
\text { loja viu o que o urso } \\
\text { fez. } \\
8 \text { - Enquanto a ursa } \\
\text { ficou esperando o } \\
\text { urso, ele foi preso. } \\
9 \text { - Depois, todos os } \\
\text { animais fizeram } \\
\text { greve, porque o urso } \\
\text { estava preso. } \\
10 \text { - O cavalo não } \\
\text { correu mais, o } \\
\text { cachorro não buscou } \\
\text { o pauzinho que seu } \\
\text { dono jogava, a vaca } \\
\text { não fez mais leite, a } \\
\text { galinha não botou } \\
\text { ovos e os que botou } \\
\text { jogou no seu dono. } \\
11 \text { - Então o juiz viu } \\
\text { os animais em greve, } \\
\text { e os animais disseram } \\
\text { que queriam morar } \\
\text { na floresta e não } \\
\text { queriam que } \\
\text { cortassem as árvores. } \\
12 \text { - O cachorro } \\
\text { depois atacou o } \\
\text { homem mal e só } \\
\text { assim o urso ficou } \\
\text { livre. } \\
13 \text { - No fim do filme, } \\
\text { o urso casou com a } \\
\text { ursa, tiveram dois } \\
\text { ursinhos e puderam } \\
\text { viver felizes na } \\
\text { floresta. }\end{array}$ & $\begin{array}{l}1^{\mathrm{a}} \\
2^{\mathrm{a}} \\
3^{\mathrm{a}} \\
4^{\mathrm{a}} \\
5^{\mathrm{a}} \\
6^{\mathrm{a}} \text { nas linhas } 3, \\
5,6,7,9,10 \\
11 \text { e } 12 \\
7^{\mathrm{a}} \text { a nas linhas } \\
2,5,6,7,8,9, \\
10,11,12 \text { e } 13 \\
8^{\mathrm{a}} \\
9^{\mathrm{a}}\end{array}$ & $\mid \begin{array}{l}2 \text { - é } \\
4 \text { - o médico, } \\
\text { já } \\
5 \text { - e } 7 \text { - na loja. } \\
11 \text { - como, } \\
\text { eles }\end{array}$ & $\begin{array}{l}2 \text { - o-um } \\
3 \text { - ajudar-ajudou } \\
4 \text { - aprende- } \\
\text { apreder, no-na, } \\
\text { ensina-ensinou, } \\
\text { o urso-este } \\
5 \text { - encontra a } \\
\text { ursa-encontrá-la, } \\
\text { sempre junto } \\
\text { brinca- } \\
\text { brincarem juntos } \\
\text { sempre. } \\
6 \text { - o-um, atira- } \\
\text { atirou, o urso-no } \\
\text { urso, foi } \\
\text { esconde-se } \\
\text { escondeu, no } \\
\text { trás-atrás, a } \\
\text { árove- de uma } \\
\text { árvore, fico } \\
\text { dormi-dormiu. } \\
7-\text { pega-pegou, a } \\
\text { urso-o urso, } \\
\text { levo-levou, na } \\
\text { loja-para uma } \\
\text { loja, a mulher-a } \\
\text { dona da loja } \\
8 \text { - o urso-ele } \\
9 \text { - tudo-todos, } \\
\text { fez greve- } \\
\text { fizeram greve } \\
10 \text { - ir correndo- } \\
\text { correu, ir pega } \\
\text { pau-buscou o } \\
\text { pauzinho, } \\
\text { gahinha-galinha, } \\
\text { fez-botou, joga- } \\
\text { jogou, o homem- } \\
\text { no seu dono. } \\
11 \text { - as-os, fez } \\
\text { greve-em greve, } \\
\text { as-os, diz- } \\
\text { disseram, quer- } \\
\text { queriam, mora- } \\
\text { morar, corta- } \\
\text { cortassem, a-as, } \\
\text { árvore-árvores } \\
12 \text { - live-livre } \\
13 \text { - fez-tiveram, } \\
\text { ursinho-ursinhos }\end{array}$ & $\begin{array}{l}2 \text { - o filme } \\
\text { começa com } \\
3 \text { - e, Dr. Do } \\
\text { Little } \\
4 \text { - para, e, e } \\
5 \text { - um dia, e } \\
\text { começou, para } \\
6 \text { - mas, e } \\
7 \text { - então, e, o, o } \\
\text { que } \\
8 \text { - enquanto } \\
9 \text { - depois, } \\
\text { resolveram, } \\
\text { porque o urso } \\
\text { estava preso. } \\
10 \text { - o, mais, o, } \\
\text { que seu dono } \\
\text { jogava, a, mais, } \\
\text { a, e os que botou } \\
11 \text { - então, e, } \\
\text { que, na, e, } \\
\text { queriam que } \\
12 \text { - depois } \\
\text { atacou, e só } \\
\text { assim, ficou } \\
13 \text { - no fim do } \\
\text { filme, com, e } \\
\text { puderam viver } \\
\text { na floresta. }\end{array}$ \\
\hline
\end{tabular}

Obs.: Cada coluna deve ser lida na vertical. Na primeira coluna, lê-se o texto original escrito pelo sujeito. Na coluna retextualizazação, lê-se o texto modificado por nós. Na coluna tipo de operação, estão explicitadas as operações de retextualização feitas nos textos. Cabe ressaltar que todas essas operações serão explicadas logo após a tabela. Nas três últimas colunas (acréscimos/alterações, eliminações e substituições) serão mostradas as modificações entre o texto original e o texto retextualizado. Essas tabelas são apenas ilustrativas do processo de retextualização, pois após cada tabela a retextualização será explicada em detalhes. 
Quanto à retextualização, nesse texto foram utilizadas a 6. ${ }^{\mathrm{a}} \mathrm{e}$ a $7 .^{\mathrm{a}}$ operações propostas por Marcuschi (2001). A 6. ${ }^{\mathrm{a}}$ operação - reconstrução de estruturas truncadas, concordâncias, reordenação sintática e novas opções léxicas - foi utilizada para a reconstrução de estruturas truncadas, concordâncias, reordenação sintática e encadeamentos. Na Linha 3 /O medico ajudar o urso/ foi necessário fazer o ajuste da concordância verbal, assim, essa frase modificou-se para /e o médico Dr. Do Little ajudou o urso/. Na linha 5 /O urso viu uma ursa e bonita, o urso encontra a ursa sempre junto brinca/ foi feito o ajuste da concordância verbal e também a reordenação sintática da frase, que ficou assim /um dia, o urso viu uma ursa bonita e começou a encontrá-la para brincarem juntos sempre/. Na linha $6 / \mathrm{O}$ homem mal atira o urso, a ursa foi esconde no trás a árove. O urso fico dormir/ também foi preciso melhorar as concordâncias das frases, e modificar algumas estruturas truncadas, como /ávore/ e /no trás/, e a frase foi então modificada para /Mas, um homem mal atirou no urso e a ursa se escondeu atrás de uma árvore. Com o tiro, o urso dormiu/. Na linha 7 /O homem mal pega o urso levo na loja, ele fez bagunça na loja. A mulher viu o urso fez na loja/ foram feitas mudanças quanto à concordância verbal, e a frase ficou assim /Então o homem mal pegou o urso e o levou para uma loja. O urso fez bagunça na loja. A dona da loja viu o que o urso fez/. Na linha 9 /Tudo os animais fez greve/, novamente modificou-se a concordância verbal para /Depois, todos os animais fizeram greve/. Nas linhas 10, 11 e 12 o mesmo processo foi feito.

A $7 .^{\text {a }}$ operação - tratamento estilístico com seleção de novas estruturas sintáticas e novas opções léxicas - também foi necessária em várias frases. Assim, na linha 2, foi acrescentada a expressão /o filme começa/ para localizar o leitor de que se trata de relato de um filme. Na linha 5 acrescentou-se a expressão /um dia/, na linha 6 /mas/, na linha 7 /então/, na linha 8 /enquanto/, na linha 9 / depois, resolveram e porque o urso estava preso/, na linha 10 /que seu dono jogava/, na linha 11 /então/ e, finalmente, na linha 12, acrescentou-se /depois atacou e só assim/ e na linha 13 adicionei a expressão /no fim do filme e puderam viver felizes na floresta/. Nota-se que a maioria dos acréscimos refere-se justamente aos articuladores textuais que Uriel não utilizou no seu texto.

Observa-se que foram feitas pouquíssimas eliminações, várias substituições, como as já mencionadas, e vários acréscimos.

$\mathrm{O}$ terceiro texto se refere a um relato da vida de Uriel. 


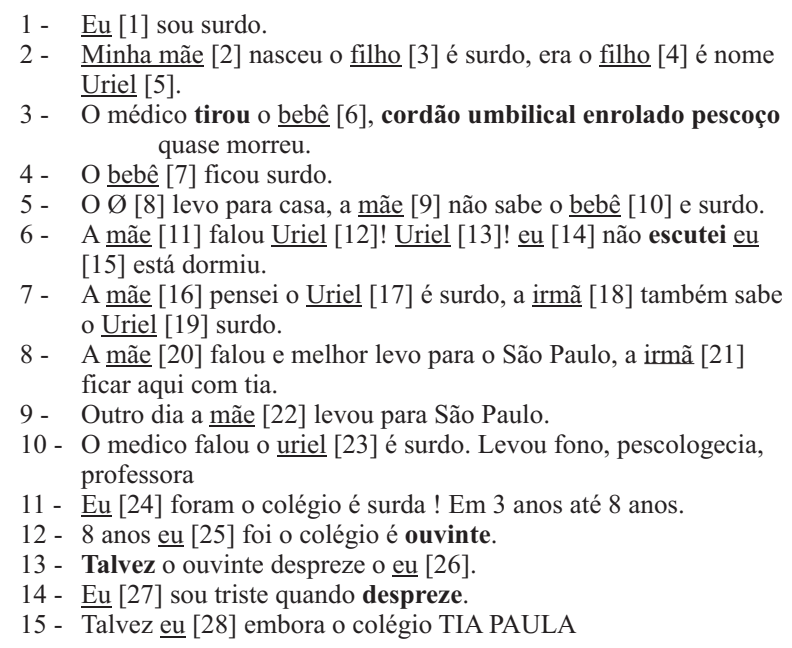

Quanto à progressão referencial, foram selecionados três referentes nesse texto: “eu”, "minha mãe" e "irmã".

Quanto ao referente "eu", houve remissão, por meio da estratégia (6), de descrição definida, em [3], [4], [6], [7] e [10]. Houve ainda a retomada, por meio da estratégia (3), de anáfora nominal, quando ele iniciou o texto com o pronome de 1. a pessoa e o retomou usando seu nome, em [5], [12], [13], [17], [19] e [23]. Nessa estratégia, o pronome "eu" resolve-se no contexto, quando o autor do texto revela seu próprio nome. E também houve a retomada, por meio da estratégia (2), de anáfora pronominal, em [14], [15], [24], [25], [26], [27] e [28].

\begin{tabular}{|l|l|}
\hline Eu [1] & Introdução ao referente \\
Filho [3], [4] & Descrição definida (6) \\
Uriel [5], [12], [13], [17], [19], [23] & Anáfora nominal (3) \\
Bebê [6], [7], [10] & Descrição definida (6) \\
Eu [14], [15], [24], [25], [26], [27], [28] & Anáfora pronominal (2) \\
\hline
\end{tabular}


Quanto ao referente "minha mãe", houve retomada, por meio da estratégia (2), de anáfora pronominal, em [8]. E, ainda, retomada, pela estratégia (1), de anáfora nominal por repetição lexical, em [9], [11], [16], [20] e [22].

\begin{tabular}{|l|l|}
\hline $\begin{array}{l}\text { Minha mãe [2] } \\
\varnothing[8] \\
\text { mãe [9], [11], [16], [20], [22] }\end{array}$ & $\begin{array}{l}\text { Introdução ao referente } \\
\text { Anáfora pronominal (2) }\end{array}$ \\
\hline
\end{tabular}

E, finalmente, para o referente "irmã", houve apenas uma retomada, por meio da estratégia de anáfora nominal (1), em [21].

\begin{tabular}{|c|l|}
\hline Irmã [18] & $\begin{array}{l}\text { Introdução ao referente } \\
\text { Irmã [21] }\end{array}$ \\
Anáfora nominal (1) \\
\hline
\end{tabular}

Nesse texto, percebe-se que Uriel vem refletindo sobre o uso das referências. Suas cadeias anafóricas estão mais longas e mais elaboradas.

Quanto à coesão seqüencial, observa-se que esta é feita tanto pela recorrência de tempos verbais, principalmente no passado, como pela pontuação. Cabe ressaltar que, na linha 5 /o bebê é surdo/ e na linha 8 /a mãe falou é melhor/, Uriel não colocou o acento no verbo /é/, o que pode causar certo estranhamento nos leitores e inclusive causar prejuízo na coerência. Ainda com relação aos verbos, nota-se inconstância com relação aos tempos verbais, já que ora os utiliza corretamente, como na linha 3 /o médico tirou o bebê/, na linha 4 /o bebê ficou surdo/, na linha 6 /eu não escutei/, ora utiliza o tempo verbal inadequado, como na linha 7 /a mãe pensei/, na linha 11 /eu foram/ e na linha 12 18 anos eu foi/. Também se percebe que Uriel vem utilizando corretamente as preposições, como na linha 5 /levou para casa/, na linha 8 /para o São Paulo/. Em outros momentos, porém, não fez uso das mesmas, como na linha $10 /$ levou fono, pescologecia, professora/, e na linha 11 /eu foram o colégio/. Esses fatos demonstram que Uriel está fazendo mais reflexões sobre a língua.

Também se percebe a continuidade tópica e o emprego de termos de um mesmo campo semântico, como /médico, cordão umbilical/. É essa progressão textual que garante a continuidade dos sentidos do texto.

Uriel também utilizou marcadores de relações espaço-temporais na linha 9, quando escreveu /outro dia/, na linha 11, quando escreveu /em 3 até 8 
anos/, na linha 12, quando escreveu /8 anos eu foi colégio/ e na linha 14 escreveu /quando/. Ressalta-se que esse marcador apresenta uma complexidade maior em relação às demais expressões de tempo. Na linha 7, Uriel fez uso do operador discursivo/também/ e do modalizador/talvez/, nas linhas 13 e 15.

Cabe ressaltar, também, que, por meio desse texto, é possível compreender como Uriel se sente em relação à sua surdez, já que, nas linhas 13 e 14 escreveu que /talvez o ouvinte despreze o eu. Eu sou triste quando despreze/, mostrando para o leitor que talvez já tenha passado por situações de preconceito e desprezo com relação aos ouvintes e que essas situações o entristecem.

Quanto à coerência, por meio da interação com Uriel foi possível entender perfeitamente todo o seu texto. Nota-se que ele utilizou expressões mais elaboradas que nos primeiros textos que produziu, o que demonstra que ele está refletindo sobre o uso do português. Assim, a retextualização dos textos se mostrou, entre outras, uma atividade importante para que Uriel percebesse o funcionamento do português.

Na retextualização, a 2. ${ }^{a}$ operação de Marcuschi (2001) - introdução da pontuação com base na intuição fornecida pela entoação das falas - foi utilizada na linha 9, que ficou da seguinte forma /O médico de lá falou: - O Uriel é surdo/

A $6 .^{\text {a }}$ operação - reconstrução de estruturas truncadas, concordâncias, reordenação sintática e encadeamentos - foi utilizada na linha 4 /O levo para casa, a mãe não sabe o bebê e surdo/, principalmente com relação à concordância; desta forma a frase foi transformada em /A mãe levou o bebê para casa, ela não sabia que ele era surdo/. Na linha 5, a expressão /está dormir/ foi modificada para /continuei dormindo/. Na linha 6, /A mãe pensei o Uriel é surdo, a irmã também sabe o Uriel surdo/ foi modificado o referente para uma anáfora pronominal, e as concordâncias também foram melhoradas, e, assim, a frase foi reestruturada para /E ela pensou: O Uriel é surdo e a minha irmã também sabia que eu era surdo/. Na linha 9, a estrutura /pescologecia/ foi modificada para / psicologia/ e a linha $10 / \mathrm{Eu}$ foram o colegio é surda! Em 3 anos até 8 anos/ foi modificada para /Depois eu fui para o colégio de surdos e fiquei lá dos 3 até os 8 anos/. Na linha 14 /Talvez o ouvinte despreze o eu. Eu sou triste quando despreze/, a concordância foi melhorada para /Talvez os ouvintes me desprezem e eu então fico triste quando isso acontece/. E, finalmente, na linha 15 /Talvez eu embora o colegio Tia Paula eu vou colégio o Integral/ foi melhorada tanto a concordância, quanto a reordenação sintática, e, assim, a frase foi modificada para /Talvez eu saia do Colégio Tia Paula e vá para o Colégio Integral/.

Foram necessárias algumas substituições, principalmente no que concerne à concordância verbal, troca de anáfora nominal de repetição lexical por anáfora pronominal e modificações de artigos para preposições. 


\section{Conclusão}

Ao longo de dois anos de acompanhamento de quatro adolescentes surdos, sujeitos desta pesquisa, foi possível realizar um trabalho de construção do português escrito em parceria com eles. Meu objetivo era participar na produção e não simplesmente aprovar ou corrigir os textos. Como Geraldi (1997), considerei a produção de textos ponto de partida de todo o processo de ensino/ aprendizagem da língua, pois é no texto que a língua se revela em toda a sua totalidade. Deste modo, o sujeito compromete-se com sua palavra e com sua formação discursiva, e tem o que dizer, uma razão para dizer o que tem que dizer, para quem dizer, e constitui-se como tal, "enquanto sujeito que diz o que diz para quem diz" (GERALDI, 1997, p.137). Em um primeiro momento, cada sujeito escreveu seu texto sem minha interferência, porém, durante as produções, eu e o sujeito partilhamos a experiência de produzir um texto em português. Debatemos idéias e discutimos a melhor forma de expressá-las em português, ou seja, interagimos, e, juntos, trabalhamos na construção dos sentidos desses textos. Em um segundo momento, por meio da prática dialógica, retextualizamos os textos, aproximando-os cada vez mais do português padrão.

Acompanhando os textos analisados dos quatro sujeitos, foi possível perceber que muitos dados vão ao encontro das pesquisas anteriores, ou seja, os sujeitos, no início do trabalho, tinham pouco conhecimento do português e este conhecimento foi aumentando ao longo do trabalho.

Além da análise com o viés da lingüística textual, outro fator fundamental na construção dos textos escritos se refere à atividade de retextualização, na medida em que, por meio desse processo, foi possível compreender e reconstruir o sentido dos textos desses sujeitos. Além disso, esse processo proporciona um exercício de compreensão do texto e de domínio dos gêneros textuais, o que possibilitou o resgate do sentido e a coerência dos textos. Por meio da retextualização, eu e os sujeitos pudemos perceber algumas diferenças e similaridades entre a língua de sinais e o português escrito; esse processo também possibilitou que os sujeitos passassem a dominar certos aspectos formais do conjunto de convenções que regulamentam o uso social da escrita. A retextualização tornou-se um exercício fundamental para o melhor desempenho desses sujeitos, além de ter sido uma grande motivação, pois eles passaram a aceitar destemidamente o desafio da escrita, manifestando mais disposição para escrever, produzindo textos cada vez mais elaborados e coerentes. 
De acordo com as análises deste trabalho, o domínio do português escrito só acontecerá por meio de seu uso constante; assim os surdos, como os ouvintes, precisam ter acesso aos diferentes tipos de textos escritos; além disso, o trabalho com a escrita deve partir daquilo que esses indivíduos já possuem, ou seja, da língua de sinais, pois é esta língua que dará toda a base lingüística para a aprendizagem de qualquer outra língua. Deste modo, as dificuldades encontradas no português escrito dos surdos podem ser referenciais para um trabalho com a escrita como segunda língua, já que não se trata apenas de ensinar a língua escrita, mas de usá-la, ou seja, fazer com que ela funcione como recurso para interação e interlocução, de maneira que o sujeito possa manipular a língua portuguesa nas suas várias possibilidades.

\section{RESUMO}

A elaboração do presente trabalho originou-se da minha inquietação com relação à aquisição da língua portuguesa em sua modalidade escrita por sujeitos surdos. Como fonoaudióloga, nos últimos dez anos de prática clínica, venho repensando questões sobre a surdez e as diferentes concepções de linguagem que caracterizam o trabalho com sujeitos surdos. Assim, partindo do fato de que há poucos trabalhos da lingüística que analisam as produções escritas de sujeitos surdos, o objetivo desta investigação é evidenciar o papel do outro na construção das produções escritas de sujeitos surdos, demonstrando que é fundamental que esse outro tenha o domínio da língua de sinais, para que sua experiência com a linguagem escrita possa ser compartilhada de forma mais efetiva. Além disso, pretendo também analisar as produções escritas de um sujeito surdo com 15 anos, com base na lingüística textual, principalmente à luz dos estudos de Koch e Marcuschi (2002), ao tratarem do processo de referenciação, e Marcuschi (2001), ao tratar do processo de retextualização. Para isso, os dados escritos foram coletados em terapias fonoaudiológicas individuais, nas quais atuei como co-autora. As análises demonstram que o surdo é capaz de escrever e aproximar seu texto do português padrão, desde que lhe sejam dadas oportunidades de interagir com a escrita por meio de atividades significativas e que haja um trabalho de parceria e atribuição de sentidos pelo leitor.

Palavras-chave: surdez, linguagem escrita, interação. 
GUARINELLO, A. C.; GREGOLIN, R. M. As produções escritas de sujeitos surdos.

\begin{abstract}
This work emerges from my questioning in relation to deaf people acquiring writing in Portuguese. The last ten years of clinical practice as a speech language therapist have enabled me to reflect about deafness and the different language conceptions that characterize the work with deaf people. As there are only a few linguistic studies that analyze the writing productions of deaf people, this study aims at clarifying the position of the other in the construction of writing productions by deaf people. It attempts to demonstrate the importance of this other person's knowledge of sign language so as to allow the experience with writing to be shared effectively. This study is a result of the analysis of writing productions of one 15 year-old deaf subject in light of textual linguistics, more specifically, the studies of Koch and Marcuschi (2002) in their discussion of referential processes, and Marcuschi (2001)'s proposal of the retextualization process. Writing data were collected during the speech language therapy sessions in which I acted as a co-author. The analysis show that deaf people are capable to write and to approach their writing to standard Portuguese, as long as they are given the opportunity to interact with writing through significant activities, and as long as there is an effort by the reader to ascribe meaning to the production.
\end{abstract}

Key-words: deafness, writing, interaction.

\title{
REFERÊNCIAS
}

COUDRY, Maria Irma Hadler. Diário de Narciso. São Paulo: Martins Fontes, 1988.

FRANCHI, Carlos. Criatividade e Gramática. In: Cadernos de estudos lingüísticos. Campinas: Unicamp, 1992.

GERALDI, José Wanderley. Portos de passagem. 4. ed. São Paulo: Martins Fontes, 1997.

KOCH, Ingedore Villaça. Desvendando os segredos do texto. 2. ed. São Paulo: Cortez, 2003.

$\mathrm{KOCH}$, Ingedore Villaça; MARCUSCHI, Luiz Antônio. Estratégias de referenciação e progressão referencial na língua falada. In: ABAURRE, M. B. M.; RODRIGUES, A. C. S. (Org.). Gramática do português falado. v. 8. Campinas: Unicamp, 2002.

MARCUSCHI, Luiz Antônio. Da fala para a escrita: atividades de retextualização. São Paulo: Cortez, 2001. 